\title{
Breast milk feeding and cognitive ability at $7-8$ years
}

\author{
L J Horwood, B A Darlow, N Mogridge
}

\begin{abstract}
Objective-To examine the association between duration of breast milk feeding and cognitive ability at 7-8 years in a birth cohort of very low birthweight infants. Design-280 survivors from a national birth cohort of 413 New Zealand very low birthweight infants born in 1986 were assessed at age 7-8 years on measures of verbal and performance intelligence quotient (IQ) using the WISC-R. At the same time mothers were questioned as to whether they had elected to provide expressed breast milk at birth and the total duration of breast milk feeding.

Results-Some $73 \%$ of mothers provided expressed breast milk and $37 \%$ breast fed for four months or longer. Increasing duration of breast milk feeding was associated with increases in both verbal IQ $(\mathbf{p}<0.001)$ and performance IQ (p< 0.05): children breast fed for eight months or longer had mean (SD) verbal IQ scores that were $10.2(0.56)$ points higher and performance IQ scores that were $6.2(0.35)$ points higher than children who did not receive breast milk. These differences were substantially reduced after control for selection factors associated with receipt of breast milk. Nevertheless, even after control for confounding, there remained a significant $(p<0.05)$ association between duration of breast milk feeding and verbal IQ: children breast fed for eight months or longer had adjusted mean (SD) verbal IQ scores that were $6(0.36)$ points higher than the scores of those who did not receive breast milk.
\end{abstract}

Conclusions-These findings add to a growing body of evidence to suggest that breast milk feeding may have small long term benefits for child cognitive development.

(Arch Dis Child Fetal Neonatal Ed 2001;84:F23-F27)

Keywords: breast feeding; very low birthweight infants; cognitive ability; intelligence quotient (IQ)

Christchurch, New

Zealand

L J Horwood

Department of

Paediatrics

B A Darlow

N Mogridge

Correspondence to:

Mr J Horwood, Christchurch Health and Development Study, Christchurch Schoo of Medicine, PO Box 4345, Christchurch, New Zealan john.horwood@chmeds.ac.nz

Accepted 7 July 2000
These studies have repeatedly shown evidence of small benefits for breast fed children over bottle fed children in terms of both improved cognitive ability and academic achievement. Lucas and others have reported various aspects of parallel studies of different feeding protocols in preterm infants and with follow up at different time periods. ${ }^{13-16}$ This group's report ${ }^{14}$ that at 7-8 years of age infants of mothers who chose to provide expressed breast milk for their infants had an average 8.3 point intelligence quotient (IQ) advantage over infants whose mothers chose not to provide breast milk greatly stimulated debate as to the reasons for the observed effects, as evidenced by the correspondence columns of the Lancet following publication of the Lucas et al report.

The aim of this study was to examine the relation between the receipt of breast milk and cognitive performance in a population based cohort of very low birthweight infants (birth weight $<1500 \mathrm{~g}$ ) assessed at $7-8$ years of age.

\section{Methods}

In 1986 all 413 New Zealand very low birthweight infants who were liveborn and admitted to a neonatal unit were included in a prospective audit of retinopathy of prematurity. ${ }^{17}$ In total, 338 children ( $82 \%$ ) survived to discharge from the neonatal unit and 12 of these died before 7 years of age. Some 298 children (96\% of surviving children living in New Zealand; $91 \%$ of all survivors) were assessed at a home visit at a mean (SD) age of 91 (5) months (1993-1994). The methodology of the follow up study has been fully reported elsewhere. ${ }^{18} 19$ At the time of the home visit, parents were asked to complete a comprehensive questionnaire on aspects of their child's health, schooling, behaviour, and family background. With respect to the provision of breast milk, mothers were asked whether they had provided breast milk at birth, including expressed breast milk, and for how long the child had received breast milk or been breast fed. The mother's retrospective recall of breast milk feeding was cross checked against the record of infant feeding practice at the time of birth. In addition, in many cases maternal recall was assisted by the Child Health Record Book. This book is provided to all mothers giving birth and provides an opportunity for the systematic recording of information on the child's health and development over the preschool period.

Children were assessed with the revised Wechsler intelligence scale for children (WISC-R), ${ }^{20}$ and verbal and performance IQ scores recorded. For 17 children $(5.8 \%$ of the 
Table 1 Mean (SD) WISC-R IQ scores by duration of breast milk feeding

\begin{tabular}{llllllll}
\hline \multicolumn{7}{c}{} & \multicolumn{2}{l}{ Duration of breast milk feeding } & & & \\
\cline { 2 - 5 } Measure & $\begin{array}{l}\text { Not breast fed } \\
(n=76)\end{array}$ & $\begin{array}{l}<4 \text { months } \\
(n=99)\end{array}$ & $\begin{array}{l}\text { 4-7 months } \\
(n=46)\end{array}$ & $\begin{array}{l}8+\text { months } \\
(n=59)\end{array}$ & $r$ Value & $p$ Value \\
\hline Verbal IQ & $94.4(18.4)$ & $97.2(18.4)$ & $101.7(17.3)$ & $104.6(14.7)$ & 0.21 & $<0.001$ \\
Performance IQ & $98.7(19.6)$ & $101.4(15.6)$ & $101.1(14.0)$ & $104.9(15.3)$ & 0.12 & $<0.05$ \\
\hline
\end{tabular}

WISC-R, revised Wechsler intelligence scale for children.

Table 2 Correlations between duration of breast feeding, IQ, and measures of perinatal status and family background

\begin{tabular}{lccc}
\hline Measure & $\begin{array}{l}\text { Duration of breast } \\
\text { milk feeding }\end{array}$ & Verbal IQ & $\begin{array}{l}\text { Performance } \\
\text { IQ }\end{array}$ \\
\hline Perinatal factors & & & \\
Sex & 0.06 & 0.05 & -0.02 \\
Multiple birth & -0.09 & 0.11 & 0.12 \\
Birth weight & -0.06 & -0.06 & $0.16^{\star \star}$ \\
Gestation & -0.00 & -0.01 & 0.08 \\
IUGR & 0.11 & 0.05 & -0.03 \\
Apgar score (5 min) & 0.01 & 0.07 & $0.17^{\star \star}$ \\
Social/family factors & -0.02 & 0.06 & 0.00 \\
Maternal age & $0.23^{\star \star \star}$ & $0.39^{\star \star \star}$ & $0.20^{\star \star \star}$ \\
Maternal education & $0.14^{\star}$ & 0.08 & 0.01 \\
Family type & $0.16^{\star \star}$ & $0.25^{\star \star \star}$ & $0.14^{\star}$ \\
Family income & $-0.16^{\star \star}$ & $-0.14^{\star}$ & -0.10 \\
Maternal smoking during & & & $-0.16^{\star \star}$ \\
pregnancy & $-0.15^{\star \star}$ & $-0.35^{\star \star \star}$ & -0.01 \\
Child ethnicity & -0.05 & -0.04 & \\
Birth order & & & \\
\hline
\end{tabular}

${ }^{\star} \mathrm{p}<0.05,{ }^{\star \star} \mathrm{p}<0.01,{ }^{\star \star \star} \mathrm{p}<0.0001$

IUGR, intrauterine growth retardation.

cohort), it was not possible to obtain a reliable assessment of IQ using the WISC-R because of associated sensorineural disability. These children have been excluded from the present analysis. One other child was excluded because data on the breast feeding measure were missing, giving an analysis sample of 280 children. (Information available from other sources-for example, specialist psychological assessments - suggested that most of the children with missing data on IQ had severe intellectual disability. A reanalysis of the data substituting an estimate of child IQ for these 17 missing cases based on the information obtained from other sources produced essentially the same conclusions as presented here, suggesting that the exclusion of these cases did not influence the estimated associations between breast milk exposure and child IQ.)

To control for potentially confounding and selection factors associated with the mother's decision to provide breast milk, a range of factors were selected from the database of the study. These factors included: $(a)$ measures of perinatal status (sex, birth weight, gestational age, whether birth weight $<10$ th percentile for gestational age (intrauterine growth retarded), multiple birth, Apgar scores); (b) measures of sociodemographic background (maternal age at the birth of the child, maternal education, family income, family type (single parent/two parent family), maternal smoking during pregnancy, child ethnicity (Maori/Pacific Island $v$ other), birth order).

STATISTICAL ANALYSIS

An initial comparison of mean IQ scores across four levels of duration of breast milk feeding (none, less than four months, four to seven months, eight or more months) was conducted using one way analysis of variance. This analy- sis showed that the association between IQ scores and duration of feeding was well approximated by a simple linear model. To examine the joint effects of all potential confounding covariates, the data were analysed using multiple linear regression techniques in which the measures of verbal and performance IQ were regressed on the four level measure of breast feeding treated as a continuous variable and significant covariate factors.

\section{Results}

In all, $73 \%$ of mothers elected to provide breast milk to their infant, with $37 \%$ breast feeding for four months or longer. Table 1 shows the associations between the duration of breast feeding and mean verbal and performance IQ scores at age 7 . In this table, the duration of breast feeding has been classified into four groups: not breast fed; breast fed for less than four months; breast fed for four to seven months; breast fed for eight months or longer. The strength of association between duration of breast feeding and each IQ measure is indicated by the product moment correlation $(r)$, and the significance of the association was tested by an $F$ test of linearity. There were small but significant associations between duration of breast milk feeding and both verbal IQ $(r=0.21$, $\mathrm{p}<0.001)$ and performance IQ $(r=0.12$, $\mathrm{p}<0.05)$. On average, children who were breast fed for eight months or longer had mean (SD) verbal IQ scores that were $10.2(0.56)$ points higher and mean (SD) performance IQ scores that were $6.2(0.35)$ points higher than children who did not receive breast milk.

Table 2 shows the correlations of the social and perinatal factors with duration of breast feeding and the measures of child IQ. The duration of breast feeding was generally unrelated to perinatal factors. However, there were clear tendencies for the duration of breast feeding to be longer in women who were better educated ( $p<0.0001)$, who lived in two parent families $(p<0.05)$ or higher income families $(p<0.01)$, who were of non-Polynesian ethnicity $(p<0.01)$, and who did not smoke during pregnancy $(p<0.01)$. The measures of child IQ showed a similar pattern of correlation with social factors, with clear tendencies for children from more socially advantaged families to have higher IQ scores. In addition, there were detectable tendencies for children of higher birth weight and with higher Apgar scores at birth to have higher performance IQ at age $7-8$ years.

On multiple linear regression, adjusting for all social and perinatal factors that were correlated with either duration of breast feeding or child IQ, the observed associations between duration of breast feeding and child IQ were substantially reduced. Table 3 shows the adjusted mean IQ scores for each level of breast feeding, the standardised regression coefficients from the fitted models, and corresponding tests of significance. After adjustment for covariates, there remained a significant association between duration of receipt of breast milk and verbal IQ $(\beta=0.12, p<0.05)$, with a 6 point advantage for infants who received breast 
Table 3 Mean WISC-R IQ scores by duration of breast milk feeding after adjustment for covariates

\begin{tabular}{llclllll}
\hline \multirow{2}{*}{ Measure } & \multicolumn{2}{l}{ Duration of breast milk feeding } & & \\
\cline { 2 - 5 } & Not breast fed & $<4$ months & 4-7 months & 8+ months & & $\beta$ Value & p Value \\
\hline Verbal IQ & 96.1 & 98.1 & 100.1 & 102.1 & 0.12 & $<0.05$ \\
Performance IQ & 99.6 & 100.8 & 102.1 & 103.3 & 0.08 & $>0.15$ \\
\hline
\end{tabular}

WISC-R, revised Wechsler intelligence scale for children.

milk for eight months or more compared with those who did not receive breast milk. There was a trend towards higher performance IQ with longer duration of receipt of breast milk but this did not reach significance $(\beta=0.08$, $\mathrm{p}>0.15)$.

\section{Discussion}

We have shown a clear and significant doseresponse relation between duration of receipt of breast milk and WISC-R IQ scores at age 7-8 years. Children who received breast milk for eight months or more had mean verbal IQ scores that were $10(0.56)$ points $(\mathrm{p}<0.001)$ and mean performance IQ scores that were 6 $(0.35)$ points $(\mathrm{p}<0.05)$ higher than the mean scores for children who did not receive breast milk. These differences were substantially reduced after statistical control for social and perinatal factors associated with receipt of breast milk: children who received breast milk for eight months or more had adjusted mean verbal IQ scores that were $6(0.36)$ points higher and performance IQ scores that were nearly $4(0.24)$ points higher than the scores for children who received no breast milk. Nevertheless, even after control for confounding factors, there remained a significant association between duration of receipt of breast milk and verbal IQ.

There are a number of criticisms which can be made of our study. Data on receipt of breast milk were collected retrospectively, although the information was often documented in the Child Health Record Book. A full feeding history was not included in the original perinatal audit. However, donor breast milk was not available in New Zealand neonatal units in 1986 and infants only received expressed breast milk from their own mothers, if at all. As in most other studies relating breast feeding to outcome, we may not have controlled for all factors that may be associated with the mother's choice to provide breast milk and may independently influence outcome for the child, including the quality of parenting, mother's own IQ, and the home environment. However, in 1986 in New Zealand, mothers were encouraged to breast feed and supported in their decision to do so, perhaps resulting in the high percentage of mothers $(73 \%)$ who did elect to provide breast milk in this study and not restricting breast feeding to only the most highly motivated mothers, as could be the case in a less supportive environment. Additional strengths of our study are that it is population based, has included over $90 \%$ of eligible children at follow up at 7-8 years of age, and involves very preterm infants who are most likely to benefit from breast milk exposure.
Although not extensive, there is a growing literature suggesting the presence of small cognitive benefits from breast feeding, with breast fed infants exhibiting higher scores on a range of measures of child cognitive development, intelligence, and academic achievement than artificially fed infants. In term samples, these benefits have been shown in preschool populations ${ }^{26-810} 11$ and school aged children, ${ }^{1-}$ 4891112 with detectable benefits even up to the point of school leaving. ${ }^{3}$ Benefits have been found in different time periods both when breast feeding was more common among lower socioeconomic status families ${ }^{1}$ and conversely when the fashion was for socially more advantaged women to breast feed. ${ }^{2-11}$ Several longitudinal studies of large $(n>700)$ general child samples have shown that the apparent benefits of breast feeding are resilient to control for confounding $^{2-8}$ and further that there is evidence of dose-response, with benefits increasing with increasing duration of breast feeding. ${ }^{2-6}$ In a recent meta-analysis of this literature, Anderson et $a l^{1}$ have estimated an advantage of between 2 and 3 points (or about $0.15-0.25$ SD units) in mean test performance for infants breast fed for a minimum of three to five months in comparison with bottle fed infants, even after control for confounding.

In any study involving correlational data, it is always possible to raise issues about uncontrolled confounders. With regard to studies of breast feeding and child cognitive development, parental cognitive ability has been suggested to be a potentially important confounder that has not been considered in most previous studies. ${ }^{22}$ In particular, two recent studies have failed to find evidence of an association between breast feeding and cognitive outcomes when measures of maternal cognitive test scores were taken into account. ${ }^{11}{ }^{12}$ However, there are at least two other well controlled studies, ${ }^{2}{ }^{10}$ one of these also of another New Zealand birth cohort, which included a measure of maternal cognitive ability in addition to other potential confounders and which were still able to find detectable statistical associations between breast feeding and child outcomes. In addition, examination of the meta-analysis by Anderson et al ${ }^{11}$ suggests that, although there may be a tendency for the estimated effects of breast feeding from studies that have included a measure of maternal cognitive ability to be at the lower end of the range of effect sizes reported in the literature, nevertheless all effect sizes are positive and suggestive of a beneficial effect for breast feeding. Thus, although parental cognitive ability may explain some component of the observed association between breast feeding and child outcomes, failure to control for this source of confounding may not be the threat to validity that some commentators suggest.

Lucas and others are one of only a very few groups to previously report studies in preterm infants, including the only attempt at a randomised controlled trial. If there are factors in breast milk, or factors that are associated with breast feeding, that are beneficial for brain development, it follows that more premature 
infants may benefit most from this form of feeding. The studies of Lucas's group involved infants of birth weight $<1850 \mathrm{~g}$, whose mothers did or did not elect to provide expressed breast milk and consisted of, firstly, infants randomised to receive either preterm formula or donor expressed breast milk as sole feeding or supplement to mother's expressed breast milk, and, secondly, infants randomised to receive either term or preterm formula as sole feeding or supplement to mother's expressed breast milk. Different subsets of the data comprising both randomised and non-randomised comparisons and with follow up at different time periods have been reported in a number of papers $^{13-16}$ and commentaries. ${ }^{23-25}$ Infants received breast milk through a nasogastric tube for a short period only (average one month). Of the first 300 children assessed at $7.5-8$ years, there was an 8.3 point IQ advantage (over half a SD) for infants of mothers who chose to provide breast milk, even after adjustment for maternal education and social class. ${ }^{14}$ This advantage remained (7.5 points) after exclusion of the 35 children who went home breast feeding. There was some evidence for a dose-response relation in that infants who received a higher proportion of their intake during the hospital period as mother's milk had higher IQ scores. Infants of mothers who chose to provide expressed breast milk but failed to do so had IQ scores no different from infants of mothers who chose not to provide expressed breast milk. ${ }^{14}$ In a randomised comparison, ${ }^{15}$ infants who received nutritionally poor donor breast milk as sole diet had similar Bayley psychomotor and mental development indices at 18 months to infants fed a more nutritious preterm formula as sole diet. By contrast, a non-randomised comparison of outcome at 18 months showed that infants who received donor breast milk as sole diet had a developmental advantage over infants receiving term formula as sole diet. ${ }^{15}$

In a letter, ${ }^{26}$ Doyle and others briefly reported outcome at 8 years of age in two groups of very preterm infants born in Victoria (85 survivors of birth weight 500-999 $\mathrm{g}$ and 124 survivors of birth weight $1000-1500 \mathrm{~g}$ ). In contrast with the UK studies, they found that infants who had received expressed breast milk, but had not been directly breast fed, had WISC-R scores not significantly different from infants who had received no breast milk. Infants who had gone on to be directly breast fed had a tendency to higher psychological test scores at age 2, 5 and 8 years. These authors suggested that the act of breast feeding rather than breast milk exposure may be the important variable associated with enhanced outcome.

In reviewing this limited evidence from preterm samples, Anderson et a ${ }^{11}$ suggest that the benefits of breast feeding may be slightly greater for preterm infants than for term infants. The results of the present study are consistent with this conclusion, with estimated effect sizes that are slightly larger than the average effect size estimated for term samples, but very similar to the average effect size for preterm samples.

Collectively, the growing evidence from studies of both term and preterm samples does suggest evidence of small beneficial effects of breast milk for child cognitive development. It is certainly biologically plausible that breast milk exposure may enhance brain development and learning ability. Breast milk contains long chain polyunsaturated fatty acids, such as docosahexaenoic acid, which accumulate in the developing brain and retina, as well as many enzymes, hormones and trophic factors, peptides and nucleotides, many of which have as yet unknown functions. ${ }^{27-29}$ However, although there is some evidence that, for instance, supplementing the diet of both term and preterm infants with long chain polyunsaturated fatty acids does lead to early enhancement of visual and cognitive function, ${ }^{30-32}$ there is as yet no convincing evidence of long term cognitive benefits.

There have been a number of proposed mechanisms to explain the observed association between breast milk exposure and subsequent enhanced cognitive status. These include suggestions that the act of breast feeding itself may affect later intelligence, that mothers who choose to breast feed may be different in some important way not controlled for in studies, or that one or more components of breast milk, as detailed above, may be lacking in formula feeds but are necessary for optimal development. There are many other accepted benefits of breast feeding, including reduced childhood infections, reduced rates of allergic reactions where there is a strong family history of atopy, and reduced rates of sudden infant death syndrome. For these reasons alone, it would not be possible to carry out a randomised controlled trial of breast feeding to further investigate the association with long term cognitive outcome. The epidemiological data do not at present allow certainty of knowledge that exposure to breast milk does or does not enhance neurodevelopmental outcome. ${ }^{33}$ Our study, in a national population based cohort of very low birthweight infants, adds to growing research evidence supporting a positive association between breast milk exposure and enhanced IQ.

Home visits were carried out by Liz Court, Anne Delwynen, Aase van der Plas, Jan Rolfe, Carolyn Sutherland, and Gill White, and we are very grateful for their skill and care. We are also very grateful to the many parents and children who took part in the study, and to numerous health professionals and teachers who answered our questionnaires. The study was funded by a project grant from The Health Research Council of New Zealand.

1 Hoefer C, Hardy MC. Later development of breast fed and artificially fed infants. $\mathcal{F A M A}$ 1929;92:615-19.

2 Fergusson DM, Beautrais AL, Silva PA. Breast-feeding and cognitive development in the first seven years of life. Soc Sci Med 1982;16:1705-8.

3 Horwood LJ, Fergusson DM. Breastfeeding and later cognitive and academic outcomes. Pediatrics 1998;101:URL: http://www.pediatrics.org/cgi/content/full/101/1/e9.

4 Rodgers B. Feeding in infancy and later ability and attainment: a longitudinal study. Dev Med Child Neurol 1978;20:421-6.

5 Taylor B, Wadsworth J. Breast feeding and child development at five years. Dev Med Child Neurol 1984;26:73-80.

6 Niemelä A, Järvenpää AL. Is breast feeding beneficial and maternal smoking harmful to the cognitive development of children. Acta Paediatr 1996;85:1202-6. 
7 Florey C du V, Leech AM, Blackhall A. Infant feeding and mental and motor development at 18 months of age in first

8 Rorn singletons. Int f Eprdemiol 1995;24(suppl 1):S21-26. opment. Early Hum Dev 1993;31:181-93.

9 Lanting CI, Fidler V, Huisman M, Touwen BCL, Boersma ER. Neurological differences between 9-year-old children fed breast-milk or formula-milk as babies. Lancet 1994;334:1319-22.

10 Morrow-Tlucak M, Haude RH, Ernhart CB. Breast feeding and cognitive development in the first 2 years of life. Soc Sci Med 1988;26:635-9.

11 Jacobson SW, Chiodo LM, Jacobson JL. Breastfeeding effects on intelligence quotient in 4-and 11-year old children. Paediatrics 1999;103:http://www.pediatrics.org/ cgicontent/ full/103/5/e71.

12 Richards M, Wadsworth M, Rahimi-Foroushani A, Hardy $\mathrm{R}$, Kuh D, Paul A. Infant nutrition and cognitive development in the first offspring of a national UK birth cohort. Dev Med Child Neurol 1998;40:163-7.

13 Morley R, Cole TJ, Powell R, Lucas A. Mother's choice to provide breast milk and developmental outcome. Arch Dis provide breast milk and
Child 1988;63:1382-5.

14 Lucas A, Morley R, Cole TJ, Lister G, Leeson-Payne C. Breast milk and subsequent intelligence quotient in children born preterm. Lancet 1992;339:261-4.

15 Lucas A, Morley R, Cole TJ, Gore SM. A randomised multicentre study of human milk versus formula and late development in preterm infants. Arch Dis Child 1994;70:F141-6.

16 Lucas A, Morley R, Cole TJ. Randomised trial of early diet in preterm babies and later intelligence quotient. $B M \mathcal{F}$ 1998;317:1481-7.

17 Darlow BA, Horwood LJ, Clemett RS. Retinopathy of prematurity: risk factors in a prospective population based study. Paediatr Perinat Epidemiol 1992;6:62-80.

18 Darlow BA, Horwood LJ, Mogridge N, Clemett RS Prospective population based study of New Zealand infants with birthweight less than 1500 grams: outcome at infants with birthweight less than 1500 grams: outcome at

19 Darlow years of age. F Paediatr Child Health 1996;33:47-51. Prospective study of New Zealand infants with birthweight less than $1500 \mathrm{~g}$ and screened for retinopathy of prematurity: visual outcome at $7-8$ years. $\mathrm{Br} \mathcal{F}$ Ophthalmol 1997;81:935-40
20 Wechsler D. Wechsler intelligence scale for children-revised. New York: The Psychological Corporation, 1974.

21 Anderson JW, Johnstone BM, Remley DT. Breast-feeding and cognitive development: a meta-analysis. Am $\mathcal{F}$ Clin Nutr 1999;70:525-35.

22 Uauy R, Peirano P. Breast is best: human milk is the optimal food for brain development. Am f Clin Nutr 1999;70:433-

23 Morley R. Diet in infancy and developmental outcome. Seminars in Neonatology 1996;1:27-34.

24 Morley R, Lucas A. Influence of early diet on outcome in preterm infants. Acta Paediatr (Suppl) 1994;405:123-6.

25 Morley R, Lucas A. The influence of early diet on outcome in pre-term infants. In: Davies DP, ed. Nutrition in human

26 Doyle LW, Rickards AL, Kelly EA, Ford GW, Callanan C. Letters to the Editor. Lancet 1992:339;744-5.

27 Lanting CI, Boersma ER. Lipids in infant nutrition and their impact on later development. Curr Opin Lipidol 1996;7:43-7.

28 Cockburn F. Breast feeding and the infant human brain. In: Davies DP, ed. Nutrition in human health. London: Royal College of Physicians, 1995:3-12.

29 Makrides M, Simmer A, Goggin M, Gibson RA. Erythrocyte docosahexaenoic acid correlates with the visual response of healthy term infants. Pediatr Res 1993;33:4247 .

30 Carlson SE, Werkman SH, Peeples JM, Wilson WM. Longchain fatty acids and early visual and cognitive development of preterm infants. Eur F Clin Nutr 1994;48(suppl 2):S27-30

31 Carlson SE, Werkman SH, Peeples JM, Wilson WM. Growth and development of premature infants in relation to $\omega-3$ and $\omega-6$ fatty acid status. In: Gali C, Simoupoulos AP, Tremoli E, eds. Fatty acids and lipids: biological aspects. Basel: Karger, 1994;75:63-9.

32 Uauy-Dagach R, Birch EE, Birch DG, Hoffman DR Significance of $\omega-3$ fatty acids for retinal and brain development of preterm and term infants. In: Gali C, Simoupoulos AP, Tremoli E, eds. Fatty acids and lipids: Biological oulos AP, Tremoli E, eds. Fatty acids
aspects. Basel: Karger, 1994;75:52-62.

33 Feldman W, Feldman FE. The intelligence on infant feeding [commentary]. Lancet 1996;347:1057. 